\title{
EFFICACY OF DIFFERENT SPAWN TYPES ON SAWDUST MEDIA
}

\author{
L Pathmashini* $^{1}$, V Arulnandhy ${ }^{1}$ and RSW Wijeratnam ${ }^{2}$ \\ ${ }^{1}$ Department of Agric. Biology, Faculty of Agriculture, Eastern University of Sri Lanka, Chenkalady \\ ${ }^{2}$ Food Technology Division, Industrial Technology Institute (ITI), Colombo - 07
}

Accepted: $30^{\text {th }}$ August 2008

\begin{abstract}
An investigation was conducted to evaluate the efficacy of four different types of grain spawns viz; kurakkan (Eleusine coracana), maize (Zea mays), sorghum (Sorghum bicolor), and paddy (Oryza sativa) on oyster (Pleurotus ostreatus) mushroom production. Spawn types were based on their effects on mushroom solids (\%), biological efficiency (BE \%), size (g), number of sporophores, yield, yield ratio and substrate weight loss (\%). Locally available kurakkan (Eleusine coracana), maize (broken) (Zea mays), sorghum (Sorghum bicolor), and paddy (Oryza sativa) were used for spawn production. The experiment was designed as a complete randomized design with three replicates. Four types of spawns were tested on a medium based on sawdust. The growing media (substrate) inoculated with kurakkan spawns showed the highest biological efficiency of $27.82 \pm 0.12(\%)$, mean yield of $52.94 \pm 0.67 \mathrm{~g}$, mushroom size of $7.73 \pm 0.33 \mathrm{~g}$ and yield ratio of $23.19 \pm 0.01$. The harvests obtained from paddy spawn showed the highest mushroom solids of $9.97 \pm 0.26(\mathrm{~g} / 100 \mathrm{~g}$ of harvest). Highest mean numbers of sporophore (fruiting bodies) were noticed in the harvests obtained from sorghum spawn $(7.67 \pm 0.66)$. The kurakkan spawn significantly. Enhanced biological efficiency and increased size and yield, when compared with other spawn types viz; maize (Zea mays), sorghum (Sorghum bicolor), and paddy (Oryza sativa).
\end{abstract}

Key Words: spawn, Pleurotus ostreatus, Eleusine coracana, Zea mays, Sorghum bicolor, Oryza sativa.

\section{INTRODUCTION}

Mushrooms are fruiting bodies of the filamentous and fleshy fungi (Chang 1981). Some mushrooms may be unpalatable, and others even poisonous, the mushrooms of many species are not only edible but delicious and nutritious (Chang and Miles 1986). Since the edible species are popularly known as mushrooms, the poisonous ones are regarded as toadstools (Chang 1981). Mushrooms belong to Ascomycotina and Basidiomycotina (Pathak et al. 2003). Some mushrooms, such as truffles and morels are Ascomycetes, but most are Basidiomycetes (Chang 1981).

The mushroom cultivation is a profitable agribusiness and oyster (Pleurotus ostreatus) mushroom is an edible mushroom having excellent flavour and taste (Shah et al., 2004). Growing oyster (Pleurotus ostreatus) mushrooms is becoming more popular throughout the world, because of their abilities to grow at a wide range of temperatures utilizing various ligno - cellulose substrates (Khan and Garcha 1984). In nature, Pleurotus species live on parts of plants which are generally poor in nutrients and vitamins. For spawn running and fruit body development, lignin and cellulose materials and vegetable wastes as well as food industry wastes are sufficient (Tautorus 1985). Many wood decomposing fungi utilize lignocelluloses efficiently and this characteristic is related to their ability to metabolise lignin (Kirk 1971).

Pleurotus species are found to be one of the most efficient lignocellulose solid state decomposing types of white rot fungi. Thus many agricultural and industrial wastes can be utilized for production of Pleurotus species as a substrate (Zadrazil and Brunnert 1981). Pleurotus have the ability to excrete hydrolyzing and oxidizing enzymes (Dougulis and Bone 1977) which have enabled them to flourish over a wide range of natural lignocellulosic waste materials like sawdust (Block et al. 1958), paddy straw (Bano and Srivastava, 1962), banana pseudo stems (Jaindaik 1974), newspaper (Hashimoto and Takahashi 1974), wheat straw (Zadrazil 1974), hulled cocoa shells (Phettipher 1987), maize cobs (Sivaprakasam and Kandaswamy, 1981),cotton wastes and sugar cane wastes (Chang 1980), sunflowers, millets, coffeebean husks, peanut shoots, pulse husks and tobacco stalks (Lelley 1988). Nowadays sawdust is intensively utilized as a mushroom substrate at commercial scale. Sawdust of soft woods such as mango and cashew favour the growth of oyster (Pleurotus ostreatus) mushroom compared to hardwood sawdust.

*Corresponding author 
The objectives of this study were to evaluate four different types of grain spawns produced and find out the most suitable grain spawn for the profitable production of oyster mushroom.

\section{MATERIALS AND METHODS}

\section{Location}

The spawn production was carried out in Industrial Technology Institute (ITI), Colombo. The evaluation experiment was carried out in a mushroom hut at the Faculty of Agriculture, Eastern University, Sri Lanka.

\section{Stock pure cultures}

Pure cultures of Pleurotus ostreatus maintained on Potato Dextrose Agar (PDA) were obtained from Industrial Technology Institute (ITI), Colombo.

\section{Spawn production}

The cleaned grains were soaked in $0.5 \% \mathrm{CuSO}_{4}$ for 10 minutes and the soaked grains were thoroughly washed and soaked in tap water for $2 \mathrm{~h}$. After that the soaked grains were drained and the excess water was removed. The additives rice bran at the rate of $10 \%$, chalk $\left(\mathrm{CaCO}_{3}\right)$ at the rate of $2 \%$, and epsom $\left(\mathrm{MgSO}_{4}\right)$ at the rate of $0.2 \%$ were added on dry weight basis of the grains and thoroughly and evenly mixed well. The polypropylene bags of 200 gauges and dimensions of $37.5 \mathrm{~cm}$ length, and 17.5 $\mathrm{cm}$ breadth were filled with this grain medium. About 200g of medium was packed in each bag. Then the bags were sealed at the neck region by putting cotton plugs into the conduit/ poly vinyl chloride pipe rings, and covered by a piece of paper by tying a rubber band around the neck. The bags were sterilized in autoclave at $121^{\circ} \mathrm{C}$ and 15 psi for 30 minutes and the sterilized bags were allowed to cool for $24 \mathrm{~h}$. Those bags were inoculated with mycelial culture of Pleurotus ostreatus which was maintained on PDA.

\section{Substrate preparation}

The medium was prepared with the ingredients of Saw dust, Rice bran at the rate of $10 \%$, Chalk $\left(\mathrm{CaCO}_{3}\right)$ at the rate of $2 \%$, and Epsom $\left(\mathrm{MgSO}_{4}\right)$ at the rate of $0.2 \%$ on the dry weight basis of the substrate. Required amounts of ingredients were taken and mixed thoroughly with sprinkling water. The correct water content was checked by pressing the medium within the hand. The medium was filled in polypropylene bags of 200 gauges, and the dimensions of $37.5 \mathrm{~cm}$ length, and $17.5 \mathrm{~cm}$ breadth. About $800 \mathrm{~g}$ of medium was filled up to $2 / 3$ of each bags.
The bags were then sealed at the neck region by putting cotton plugs into the conduit/ poly vinyl chloride pipe rings, and covering by a piece of paper by tying a rubber band around the neck. Sealed bags were sterilized in an autoclave at $121^{\circ} \mathrm{C}$ and 15 psi for 30 minutes and the sterilized bags were allowed to cool for $24 \mathrm{~h}$. Those bags were immediately inoculated with spawn prepared earlier. Approximately $2 \mathrm{~g}$ of spawn was inoculated into the saw dust substrate bags under the laminar flow cabinet and incubated at $30 \pm 2{ }^{\circ} \mathrm{C}$, under dark.

\section{Harvesting, determination of yield, size and Bio- logical efficiency ( BE )}

When the caps of mushrooms fully expanded, harvesting commenced. Mushrooms were harvested, counted and weighed daily. At the end of the third flush, yield and BE were determined and average mushroom size was calculated as fresh weight of mushrooms harvested divided by the number of mushrooms. BE was determined as the ratio of fresh mushrooms harvested (g) per dry substrate and expressed as percentage. Yield was the weight of the mushrooms totally harvested up to three harvests. The total yield was divided by number of harvests to obtain mean yield value.

\section{Mean number of sporophores}

Total numbers of sporophores (fruiting bodies) harvested in all three harvests divided by number of harvests.

\section{Mushroom solids}

The methodology was adopted according to Mamiro and Roysee (2007). Fresh mushrooms for solids content determination were randomly sampled from each treatment. Mushrooms were sliced into quarters or eighths depending on the original mushroom size. Samples $(10 \mathrm{~g})$ were placed in a paper bag and oven dried at $60^{\circ} \mathrm{C}$ for $48 \mathrm{~h}$. Dried mushrooms then allowed to cool before weighing. Three replicates per treatment were used and solid content was recorded as percentage dry mushroom weight.

\section{Yield ratio}

Yield ratio was determined as the ratio of total fresh weight of mushrooms harvested to the unit fresh weight of the substrate used.

\section{Substrate weight loss percentage}

Substrate weight loss percentage for harvest 1 was determined as the ratio of loss in the substrate initial weight $(\mathrm{g})$ per weight of substrate after the first harvest and expressed as percentage. Substrate 
weight loss percentage for second and third harvests were determined as the ratio of loss in the substrate initial weight after the previous harvest (g) per weight of substrate after each harvest and expressed as percentage.

\section{Experimental design and data analysis}

The experiment was designed as complete randomized design (CRD) with three replicates and Data were analyzed using the analysis of variance (ANOVA) procedure by SAS and means were separated using Duncan's Multiple Range Test (DMRT) at the 5\% probability level. Correlation studies were done by using SPSS11.0 package.

\section{Spawn types tested}

Four types of spawn tested were Paddy spawn, broken popcorn Maize spawn, Sorghum spawn, and Kurakkan spawn.

\section{RESULTS}

\section{Yield, Mean yield, and yield ratio}

There were significant differences found in the mean yield of three harvests among the four different spawn types (Table 1). Kurakkan showed the highest mean yield of $46.37 \pm 0.67 \mathrm{~g}$ followed by sorghum, broken popcorn maize, and paddy as $39.45 \pm 0.67 \mathrm{~g}, 19.72 \pm 1.37 \mathrm{~g}$, and $15.92 \pm 0.37 \mathrm{~g}$ respectively.

Highest yield ratio was noticed in the harvests obtained from kurakkan spawn as $23.19 \pm 0.01$ and significantly differed from other three spawn types. Next to kurakkan sorghum expressed an acceptable yield ratio of $19.72 \pm 0.05$ and significantly differed from maize and paddy.

\section{Size}

Highest mushroom size of $7.73 \pm 0.33 \mathrm{~g}$ was recorded in the harvests obtained from kurakkan spawn and significantly differed from other three types of spawns.

\section{Mushroom solids}

The harvest obtained from paddy spawn showed the highest mushroom solids of $9.97 \pm 0.26(\mathrm{~g} / 100 \mathrm{~g}$ of harvest) and significantly differed from the other three types of spawns (Table 1).

\section{Biological Efficiency}

Spawn types showed the interaction with substrates. They significantly differed in biological efficiency as well. The growing media (substrate) inoculated with kurakkan spawn showed the high-

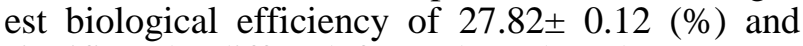
significantly differed from the other three spawn types.

\section{Mean number of sporophores}

Highest mean number of sporophores (fruiting bodies) was noticed in the harvests obtained from sorghum spawn as $7.67 \pm 0.66$ and significantly differed from the other three spawn types. Next to the sorghum, kurakkan showed $6.00 \pm 0.33$ mean number of sporophores and it is significantly differed from paddy and maize spawns.

\section{Substrate weight loss percentage}

The substrate spawned with kurakkan spawn showed maximum substrate weight loss \% of $62.97 \pm 0.07$ and it is significantly differed from other three spawn types.

Table 1: Efficacy of different spawn types on sawdust

\begin{tabular}{|c|c|c|c|c|}
\hline \multirow[t]{2}{*}{ Parameter } & \multicolumn{4}{|c|}{ Spawn Types $^{+++}$} \\
\hline & Sorghum & Kurakkan & Maize & Paddy \\
\hline M. Solids ${ }^{+}(\%)$ & $8.68 \pm 0.19^{b}$ & $8.84 \pm 0.53^{b}$ & $9.02 \pm 0.10^{b}$ & $9.97 \pm 0.26^{a}$ \\
\hline $\mathrm{BE}^{* *}(\%)$ & $21.67 \pm 0.33^{b}$ & $27.82 \pm 0.12^{\mathrm{a}}$ & $13.15 \pm 0.33^{c}$ & $9.94 \pm 0.10^{\mathrm{d}}$ \\
\hline $\operatorname{Size}^{++}(\mathrm{g})$ & $5.14 \pm 0.43^{b}$ & $7.73 \pm 0.33^{\mathrm{a}}$ & $5.38 \pm 0.033^{b}$ & $4.34 \pm 0.06^{\mathrm{c}}$ \\
\hline Mean No. ${ }^{* * *}$ & $7.67 \pm 0.66^{\mathrm{a}}$ & $6.00 \pm 0.33^{b}$ & $3.67 \pm 0.57^{\mathrm{c}}$ & $3.67 \pm 0.33^{c}$ \\
\hline Mean Yield*(g) & $39.45 \pm 0.67^{b}$ & $46.37 \pm 0.67^{a}$ & $19.72 \pm 1.37^{\mathrm{c}}$ & $15.92 \pm 0.37^{\mathrm{d}}$ \\
\hline Yield $^{\Phi}$ & $118.34 \pm 0.29^{b}$ & $139.12 \pm 0.30^{\mathrm{a}}$ & $59.15 \pm 0.30^{c}$ & $47.77 \pm 0.30^{d}$ \\
\hline Y ratio ${ }^{\dagger}$ & $19.72 \pm 0.05^{b}$ & $23.19 \pm 0.01^{\mathrm{a}}$ & $11.86 \pm 0.67^{\mathrm{c}}$ & $9.96 \pm 0.67^{\mathrm{c}}$ \\
\hline $\mathrm{WL}(\%)^{\mathbb{I}}$ & $58.39 \pm 0.62$ & $62.97 \pm 0.07$ & $45.89 \pm 0.30$ & $44.83 \pm 0.04$ \\
\hline
\end{tabular}

* Mean yield, Fresh mushrooms harvested on three harvests, + Mushroom solids at third harvests, as percent dry mushroom weight, ** Biological Efficiency, ratio of fresh mushroom harvested/ initial dry weight of substrate expressed as a percentage, ++ Size, ratio of total fresh weight (yield)/ total numbers of sporophore (fruiting bodies), *** Mean number of sporophores, Number of sporophores (fruiting bodies) of three harvests, $\Phi$ Total Yield of three harvests, + Y ratio, ratio of total weight of mushrooms harvested to the unit fresh weight of substrate., 9 Weight Lost $\%=$ Weight of the substrate after harvest/ Initial weight of the substrate, $+++=$ Standard Deviation of mean three replicates. a, b, c = Duncan Grouping. Figures followed by same letter in each row do not differ significantly at $\mathrm{p}=0.05$ based on DMRT 


\section{DISCUSSION}

\section{Yield, mean yield and yield ratio}

In this study conducted in ambient environment without any modifications in atmosphere. The yield obtained was found to be very lower than Shah et al., (2004) but superior than others. Obodai and Vowotor (2002) obtained 25.5g of mean yield Pleurotus ostreatus. Kurakkan and sorghum spawns expressed superior values than Obodai and Vowotor (2002).

Further Bano and Srivastava (1962) noticed 22 $\mathrm{g}$ of total fresh weight when spawned with paddy spawn. The total yield obtained was seemed to superior that of Bano and Srivastava (1962) noticed $22 \mathrm{~g}$ of total fresh weight. And also Arulnandhy and Gayathri (2007) obtained 24g of mean yield on sawdust medium. When comparing these workers we obtained superior mean yields in sorghum (39.45 g) and kurakkan (46.37 g) spawns.

Bano and Srivastava (1962) obtained $60 \mathrm{~g}$ of mean yield by using sawdust and paddy straw to the ratio of $1: 1$, while Arulnandhy and Gayathri (2007) obtained $55 \mathrm{~g}$ for the same substrate composition. When the saw dust incorporated with dry leaves Arulnandhy and Gayathri (2007) obtained 22 $\mathrm{g}$ of mean yield and when it was incorporated with shredded paper they noticed $47 \mathrm{~g}$. Saw dust incorporated with substrates like straw and grasses (Udugama and Ranjani, 1997), shredded paper (Arulnandhy and Gayathri, 2007) enhanced the yield to a certain extent rather than saw dust alone.

However in contrast Shah et al., (2004) noticed $646.9 \mathrm{~g}$ of maximum yield of three harvests through a different technology of cultivation where they have adopted fermentation of substrates (sawdust) for five days to boost the yield and the temperature which was maintained at $17-20{ }^{\circ} \mathrm{C}$ throughout the period of fructification (flush forming). The reduction in maximum yield in current study would have been due to the prevailing environmental condition during the study period.

Kurakkan expressed highest yield ratio of 23.19 \pm 0.01 and significantly differed from other spawn types. Yield ratio and yield are positively correlated, thus increase in yield enhance yield ratio. Yield ratio may be affected by substrate composition.

This was found increased biological efficiency was enhanced the total, mean yield and yield ratio by efficient transformation of substrates into mushroom fruit bodies.

\section{Size}

The mean size of the mushroom is essential for market purpose. The largest fruiting body sizes were obtained in kurrakkan spawn. The largest mushroom (fruiting body) size positively correlated with the yield. (Correlation factor $=+0.777$ ) As the total yield increases, the size of individual mushroom also increased. Biological efficiency enhanced the utilization of substrates and accumulation of the biomass into mushroom fruiting bodies and thus improved individual mushroom size.

\section{Mushroom solids}

The highest mushroom solids obtained through paddy spawn. This may due to the interaction of paddy spawn with the substrate. This interaction would be enhanced the accumulation of more solids (nutrients) in final yield. Mushroom solids were found to negatively correlated with total yield $($ Correlation factor $=-0.691)$.

\section{Biological efficiency}

Highest biological efficiency was found in kurakkan spawn. The result could have been due to the efficient and effective utilization of sawdust by Pleurotus ostreatus when spawns are produced in kurakkan. Shah et al., (2004) who noticed $64.69 \%$ of biological efficiency by utilized fermented sawdust substrate. Obodai and Vowotor, (2002), also obtained 50.93\% of BE for Pleurotus ostreatus. Howeverfindings in this experiment seemed superior to Nout and Keya (1986), who recorded biological efficiency of 5\% for Pleurotus ostreatus on sawdust at ambient environmental conditions.

$\mathrm{BE}$ was found to be strongly and positively correlated with yield (Correlation factor $=+0.999$ ).

\section{Mean number of sporophores}

Even sorghum showed lower yield than kurakkan, sorghum expressed higher sporophore forming potential. The mean number of sporophores noticed in kurakkan and sorghum spawns were in agreement with Shah et al., (2004) who noticed 7.11 - 12.11 numbers as mean of three harvests on sawdust while Arulnandhy and Gayathri (2007) noticed 8 numbers. Number of sporophores were found to be negatively correlated with total yield (Correlation factor $=-0.778$ )

\section{Substrate weight loss percentage}

Substrate weight loss percentage directly correlated to yield as well as BE. As yield increases, the substrates effectively assimilated into yield, thus substrate weight loss percentage become high. 


\section{CONCLUSION}

The growing media (substrate) inoculated with kurakkan spawn showed the highest biological efficiency of $27.82 \pm 0.12(\%)$, mean yield of $52.94 \pm$ $0.67 \mathrm{~g}$, mushroom size of $7.73 \pm 0.33 \mathrm{~g}$ and yield ratio of $23.19 \pm 0.01$. The harvest obtained from paddy spawn showed the highest mushroom solids of $9.97 \pm 0.26(\mathrm{~g} / 100 \mathrm{~g}$ of harvest). Highest mean numbers of sporophore (fruiting bodies) were noticed in the harvests obtained from sorghum spawn as $7.67 \pm 0.66$. The kurakkan spawn enhanced biological efficiency and increased size and yield, thus kurakkan was found to be the best spawn among the spawn types tested.

\section{ACKNOWLEDGEMENT}

We express our sincere gratitude to world bank funded IRQUE project for providing adequate funds to complete this research successfully.

\section{REFERENCES}

Arulnandhy V, Gayathri T 2007 Identification of suitable and efficient substrate for the production of oyster (Pleurotus ostreatus) mushrooms. B.Sc. Thesis. Department of Agricultural Biology, Faculty of Agriculture, Eastern University, Sri Lanka

Bano Z and Srivastava HC 1962 Studies on the cultivation of Pleurotus species on paddy straw. Food Sc. 11(12): $363-365$.

Block SS, Tsao G and Han LH 1958 Production of Mushrooms from sawdust. J. Agr. Food Chem. 6: $923-927$.

Chang ST 1980 Mushrooms as human food. Bioscience 30 (6): $399-401$.

Chang ST 1981 Mushrooms and Mushroom Science.MUSH.J.Tropics 13$): 2-4$.

Chang ST and Miles PG 1986 Mushroom technology. Mushroom Newsletter for the tropics 6(4): 6 -11.

Daugulis AJ and Bone DH 1977 Submerged cultivation of edible whote rot fungi on tree bark. Eur. J. Appl. Microbiol. 4: 159 - 168.
Jandaik CL 1974 Arttificial cultivation of Pleurotus sajor - caju. MUSH. J. Tropics 1(2): 34 - 35

Hashimoto K Takahashi Z 1976 Studies on the growth of Pleurotus ostreatus. Mush Sc. 9(1): 585 - 593.

Khan P and Garcha HS 1984 Pleurotus mushroom, A source of food protein. Mush. Newsletter. Trop. 4, 9 -14 .

Kirk TK 1971 Effects of microorganisms on lignin. Ann. Rev. Phytopath 9, $185-210$

Lelley J 1988 Growing Edible Mushrooms - Still a Generally Neglected Opportunity. GATE $4: 30-34$.

Mamiro DP and Royse DJ 2008 The influence of spawn type and strain on yield, size and mushroom solids content of Agaricus bisporus produced on noncomposted and spent mushroom compost, Bioresour.Technol. 99 (8): 3205 - 3212. Retrieved on www.sciecedirect.com as on 07/08/2007.

Nout MJR and Keya SO 1983 Cultivation of Pleurotus sajor - caju in Kenya. Mushroom Newsletter for the tropics 4(2): $12-14$.

Obodai M and Vowotor KA 2002 Performance of different strains of Pleurotus species under Ghanaian conditions. J. Food Technol. in Africa. 7( 3 ): pp. 98-100.

Pathak VN, Yadav N and Gaur M 2003 Mushroom Production and Processing Technology. AGRIBIOS, India.

Phettipher GL 1987 Cultivation of the Oyster Mushroom (Pleurotus ostreatus) on lignocellulotic waste. J.Sci. Food. Agric. 41: 259 - 269.

Shah ZA, Ashraf M and Ishtiaq M 2004 Comparative Study on Cultivation and Yield performance of Oyster Mushroom (Pleurotus ostreatus ) on Different Substrates (Wheat Straw, Leaves, Sawdust). Pak. J. Nutri. $3: 158-160$.

Sivaprakasam K and Kandaswamy TK 1980 Cultivation of Pleurotus sajor - caju on farm wastes in Tamil Nadu. RRAI Symp. PAU, Ludhiana, pp. $369-374$.

Tautorus ET 1985 Mushroom Fermentation. Adv. Biotechnol. Process. 5: $227-273$.

Zadrazil F and Brunnert F 1981 Investigation of physical parameters important for the solid state fermentation of straw by white rot fungi. Eur. J. Appl. Microbiol. 11: $183-188$.

Zadrazil F, 1974 The ecology and industrial production of Pleurotus ostreatus. Mush. Sc. 9: 621 - 652. 